\title{
UN SENDERO SEMIOLÓGICO-LINGÜÍSTICO: LAS LECCIONES DE ÉMILE BENVENISTE
}

Sobre Émile Benveniste. Últimas Lecciones. Collège de France 1968-1969. Buenos Aires: Siglo Veintiuno, 2014. 224 pp.

Silvina Palillo

UNR

Este libro está estructurado en diferentes partes: la central responde a las últimas lecciones dictadas por el célebre lingüista Émile Benveniste en el Collège de France, durante los años 1968 a 1969. En primer lugar, esta parte dialoga con las que están al comienzo y al final del libro, que sirven de marco general para que el lector pueda no sólo comprender la obra de Benveniste, sino también situarse en el contexto de producción. En segundo lugar, el mismo texto que corresponde a sus lecciones es una construcción de sus manuscritos y de las notas de algunos de los estudiantes presentes en esas clases. Por otro lado, el libro también presenta ilustraciones que corresponden a anotaciones originales del lingüista, las cuales se encuentran actualmente en la Biblioteca Nacional de Francia. Ciertamente, este texto es una invitación a recorrer la vida de Émile Benveniste: una vida ligada y dedicada a la Lingüística.

La parte central está dividida en tres secciones, así, la primera se titula "Semiología" y abarca las primeras siete lecciones; la segunda, "La lengua y la escritura", abarca las lecciones octava a quinceava; por último, la tercera sección, "Última lección, últimas notas", responde a la única lección 
que Benveniste pudo dictar en el período 1969-1970, dado que el 6 de diciembre de 1969 sufrió un accidente cerebrovascular que lo paralizó y lo dejó afásico, por lo cual no pudo continuar dictando sus clases. En el primer apartado - "Semiología" Benveniste parte del interrogante sobre qué es significar. Luego retoma los postulados de Saussure y Peirce al respecto de los signos y la semiología. Las tres últimas lecciones de esta primera sección las dedica a los planteos propios vinculados a la relación de interpretación de sistemas semiológicos (Cf. p. 91 y sgtes.). Postula que entre el lenguaje y otros sistemas semiológicos existe una relación de engendramiento, dado que concibe que no existe ningún sistema por fuera del lenguaje. El segundo apartado - "La lengua y la escritura" - constituye una novedad, puesto que no había sido planteada en otro trabajo suyo esta relación. En dicha sección, se propone reflexionar en torno a la escritura como sistema semiológico. Asimismo, pone en consideración, con un cuidado minucioso, distintos sistemas de escritura, tales como el de Egipto antiguo, el de la Mesopotamia, la escritura china, la escritura cuneiforme, las tablillas de escritura pertenecientes a algunas culturas, entre otras. Uno de los interrogantes que sirve de base a su presentación es cómo se memorizaban los mensajes en las civilizaciones antiguas. Esto pone de manifiesto la relación entre escritura y mensaje, dado que para recordar los mensajes a ser transmitidos, se contaba con diferentes ayudamemorias: marcas grabadas en objetos, pictografías, entre otros. Luego, también aborda los sistemas silábicos hasta llegar a los fonéticos. Todo esto lo lleva a considerar la escritura como "instrumento de autosemiotización de la lengua" (p. 127) y a vincular la lengua y la escritura en cuanto al hecho de que significan de la misma manera. En el tercer apartado - "Última lección, últimas notas"- Benveniste retoma la idea central: la significación. Observa que sin ésta "la lengua no es nada" ( $p$. 154). Esta idea la recoge de los postulados de Saussure y la 
enriquece, dado que además se refiere a los signos pertenecientes al enunciado. Por último, señala que la semiología es el estudio del sentido, es decir, de la manera de significar de todos los elementos presentes en la lengua.

Como mencionamos al comienzo, hay una serie de textos que entran en diálogo con las lecciones de Benveniste. Estos son: el Prefacio, titulado "Émile Benveniste, un lingüista que no dice ni oculta, sino que significa", escrito por Julia Kristeva; la "Introducción", de Jean-Claude Coquet e Irène Fenoglio; además, los anexos y el posfacio que se presentan al final del libro. Así, el primer anexo es "Biobibliografía de Émile Benveniste", a cargo de los editores, y "Émile Benveniste (1902-1976)", a cargo de Georges Redard. El segundo anexo se titula "Los papeles de Émile Benveniste", de Émilie Brunet; y la obra concluye con el Posfacio intitulado "Émile Benveniste, el destino de un estudioso", a cargo de Tzvetan Todorov.

En el Prefacio, Julia Kristeva inserta a Benveniste en la tradición lingüística, no sólo a través de datos biográficos y en cuanto a sus estudios, sino también a través de una lectura cuidada y atenta de los ejes vertebradores de su obra. Una de las cuestiones clave que destaca es el hecho de significar como algo que trasciende a la unidad signo, dado que Benveniste refiere a este hecho tanto en la lengua como en la escritura. Por otra parte, hace referencia a la vinculación que hemos señalado entre vida y profesión: "Benveniste es un hombre que hizo del lenguaje el camino de una vida" (p.21).

De la Introducción de Jean-Claude Coquet e Irène Fenoglio, destacamos el hecho de que refieren a qué es lo inédito de este libro. En respuesta a esto, señalan que, por un lado, lo son reflexiones últimas de Benveniste, como así también, el hecho de que se presente la faceta de docente del lingüista. Respecto 
de las reflexiones, se refieren a las que tratan sobre la escritura y a sus relaciones con el sistema de la lengua.

En el primer anexo, el lector se sumerge en los avatares de la vida del lingüista. Una de las cuestiones a este respecto que destaca Redard es el enorme conocimiento de distintas lenguas que Benveniste desarrolla a partir de viajes a distintas partes del mundo. En dichos viajes, estudia con dedicación las lenguas de las poblaciones en cuestión, las que luego describe. Los ámbitos en los que Redard centra las actividades principales de Benveniste son: el indoeuropeo, el iranio y la lingüística general.

El segundo anexo refiere principalmente a la obtención de los manuscritos. La voluntad de Benveniste estuvo en legarlos a la Biblioteca Nacional de París, para lo cual invistió a su hermana y al profesor Redard como legatarios de su obra. También el anexo refiere a otros papeles que se encuentran en el Collège de France y a libretas en las que tomaba notas sobre sus investigaciones en torno a las lenguas amerindias. Estas últimas están en la Universidad de Fairbanks (Estados Unidos).

El Posfacio podemos concebirlo como una llave al aula en la cual dictaba clases el lingüista. Utilizamos dicha metáfora dado que se trata, en parte, de un relato vivencial de Todorov en algunas clases de Benveniste, a las cuales el crítico literario había asistido para poder trabajar la Literatura a partir de la materia verbal de la que están hechas las obras literarias (Cf. p. 203). En relación a la obra de Benveniste, Todorov sentía una fuerte atracción sobre todo en lo que se refiere al sentido y a la enunciación.

Los conceptos signo y semiología, que se constituyen en claves en la lectura, ya habían sido trabajados por el lingüista con antelación. En su obra Problemas de lingüística general, le dedica varios apartados a esta cuestión. Recordemos que allí retoma 
las definiciones de Saussure, al igual que lo hace en el texto que reseñamos; pero es importante señalar que no presenta estos conceptos del mismo modo. Así, en Problemas de lingüistica general señala que debe superarse la noción saussureana (Cf. Benveniste, ed. 2001: 69), aunque no logra perfilar de qué modo debe hacerse. Además, afirma que considera necesario un planteo en torno a la escritura, pero simplemente esboza esta problemática, deteniéndose solamente en la oralidad. Como hemos mencionado en los párrafos precedentes, los conceptos signo y semiología se desarrollan minuciosamente en Últimas lecciones: la noción signo es abordada según los postulados de Saussure, Peirce y la propia postura de Benveniste. Asimismo, se tiene en cuenta la escritura como un sistema semiológico y se abordan las relaciones entre este y el sistema de la lengua.

Por último, podemos señalar que a partir de este libro, la obra de Benveniste se actualiza y se enriquece. Así, el lector se sumerge en la vida del lingüista, a partir del detalle con el que se brindan los datos vinculados a sus investigaciones, de sus lecciones, y de los críticos y lingüistas que abren y cierran el libro, cuyas voces dotan a la obra de un carácter único que nos permite recorrer el sendero semiológico-lingǘrtico de su vida. 